\title{
ASPECTOS FILOSÓFICOS, SOCIOLÓGICOS, POLÍTICOS E PEDAGÓGICOS DA EDUCAÇÃO INFANTIL
}

\author{
Alessandra Glaucia Castilho da Silva ${ }^{1}$ \\ Elidiane Benedita da Silva ${ }^{2}$ \\ Jucinéia Xavier dos Santos ${ }^{3}$ \\ Luciana Xavier Cirino ${ }^{4}$ \\ Rejane Aparecida Prado Jesus Lima ${ }^{5}$ \\ Vânia Valesca Castilho da Silva Santos 6
}

RESUMO: O presente artigo tem como temática interdisciplinar: "Aspectos filosóficos, sociológicos, políticos e pedagógicos da Educação Infantil”, sendo que esta temática foi escolhida para possibilitar a aprendizagem desses conteúdos tão indispnesáveis para todos os educadores. O profissional que atua na educação, mais designadamente na área da Pedagogia, deve realizar articulações entre disciplinas como a Filosofia e a Sociologia, bem como ter domínio acerca dos documentos legais que regem a Educação em nosso país.

Palavras-chave: Educação Infantil. Aprendizagem. Pedagogia.

ABSTRACT: This article has as interdisciplinary theme: "Philosophical, sociological, political and pedagogical aspects of Early Childhood Education", and this theme was chosen to enable the learning of these contents so essential for all educators. The professional who works in education, more specifically in the area of Pedagogy, must make connections between disciplines such as Philosophy and Sociology, as well as mastering the legal documents that govern Education in our country.

Keywords: Early Childhood Education. Learning. Pedagogy.

\footnotetext{
${ }^{1}$ Graduada em Pedagogia pelas Faculdades Integradas Matrogrossense de Ciências Sociais e Humanas mantida pelo ICE - Instituto Cuiabano de Educação, Especialista em Educação de Jovens e Adultos pela FAE - Faculdade das Águas Emendadas.

${ }^{2}$ Graduada em Pedagogia pela UNIC - Universidade de Cuiabá, Especialista em Neuroeducação pela FEICS

- Faculdade Evangélicas Integradas Cantares de Salomão.

${ }^{3}$ Graduada em Pedagogia pela Universidade Estadual de Tocantins, Especialista em Educação Infantil e Letramento pela Faculdade INVEST de Ciências e Tecnologias.

${ }^{4}$ Formação Ensino Técnico Magistério pelo Instituto de Educação Carlos Pasquale.

${ }^{5}$ Graduada em Pedagogia pela Unopar - Universidade Norte do Paraná, Especialista em Educação Infantil: Concepção de Infância e Trabalho Educativo com Ênfase em Alfabetização e Letramento pela Faculdade Afirmativo.

${ }^{6}$ Graduada em Pedagogia pela Faculdade INVEST de Ciências e Tecnologias, Especialista em Educação Infantil pelo IESMIG - Instituto de Ensino Superior de Minas Gerais.
} 


\section{INTRODUÇÃO}

Este artigo está relacionado aos conteúdos interdisciplinares: Aspectos filosóficos, sociológicos, políticos e pedagógicos da Educação Infantil, como competência levar os educadores a: aprender a fazer uma leitura crítica da realidade por meio do aporte teórico, como habilidades o mesmo pretende sistematizar o conhecimento.

Como objetivos de aprendizagem: conhecer o conceito de infância e como ele se construiu historicamente; compreender os aspectos legais vigentes na Educação Infantil; ler e analisar criticamente os textos sugeridos; sintetizar os conhecimentos e reflexões realizadas pelo grupo em um texto.

É imprescindível, que o desenvolvimento da consciência crítica aconteça desde a Educação Infantil, pois se trata da primeira etapa da educação básica, deste modo, a base para a construção de conhecimentos que deverão dar oportunidade para intervir na sociedade.

$\mathrm{Na}$ Filosofia, realizar o exercício reflexivo sobre o modelo atual de Homem, sociedade e de educação e na Sociologia analisar a formação da sociedade e os seus reflexos no espaço educativo. Para a compreensão dos aspectos legais vigentes na Educação Infantil, foco desse artigo, é preciso partir do conhecimento do conceito de infância e como ele se construiu historicamente.

Essas reflexões são indispensáveis para sua prática na educação básica, pois o papel do professor é socializar os conhecimentos científicos estabelecidos durante a história da humanidade juntamente com os alunos para que possam atuar de modo crítico, na realidade social com emancipação e reflexão, objetivando a construção de uma sociedade e igualitária e justa.

A elaboração deste artigo apresenta importância, na medida em que permite contribuir para a formação continuada dos educadores, ou seja, tem por objetivo promover a construção de saberes docentes na formação do sujeito crítico. 


\section{DESENVOLVIMENTO}

A evolução do ser humano é baseada em transformações físicas, psíquicas e comportamentais. A concepção de infância de séculos atrás é totalmente distinta de hoje em dia, sendo que esta, é uma melhor forma de lhe dar com o desenvolvimento físico e intelectual da humanidade fundamentado no respeito e articulação de cada fase da vida de um indivíduo. No que se trata do primeiro processo da vida têm-se a obrigação de diferenciar-se algumas palavras que, à princípio, são compreendidas erroneamente como sinônimos.

No século XVI, o conceito de infanda começa a obter um caráter de estrutura social e psicológica, (lembrando que ainda não se tinha a concepção de desenvolvimento infantil), chegando mais aprimorado aos dias atuais. Já no século XV, como fator de rica contribuição para o conceito de infância, mais bem elaborado no século $X$ VI, foi o surgimento da prensa tipográfica que, por sua vez, criou uma nova forma de conceber a idade adulta, pois uma nova simbologia se instalava, a escrita, a leitura e a reflexão, destinadas aos adultos. Dessa forma, as crianças foram excluídas do universo adulto, o que fez que surgisse outro hábitat, a infância (BARROS, 2009, p. 82).

As concepções de infância e criança, sendo a primeira compreendida, em síntese, como uma etapa da vida da pessoa e, a segunda, como sujeito histórico, social e cultural.

[...] infância e demais cognatos, em sua origem latina e nas línguas daí derivadas, recobrem um campo semântico estreitamente ligado à idéia de ausência de fala. Esta noção de infância como qualidade ou estado do infante, isto é, d'aquele que não fala, constrói-se a partir dos prefixos e radicais lingǘsticos que compõem as palavras (LAJOIO, 2006, p. 229 apud BAMBINI, 2013, p. 7).

O conceito de infância foi historicamente sendo construída, perpassando pelo o adulto em miniatura na Idade Média e chegando a criança cidadã na Contemporaneidade.

A concepção da infância social e historicamente construída é, portanto, altamente temporal e suscetível a mudanças. E hoje? Como é vista a criança? Qual a concepção de infância que os adultos possuem das crianças? E qual é a necessidade da infância de hoje? Que espaço a criança possui para colocar-se, para viver o seu corpo, para se expor à experiência, para mostrar seus sentimentos e pensamentos? (PORTILHO, 2017, s/p).

Fernandes e Kuhlmann Júnior (2004, p. 29), apontam que:

Os fatos relativos à evolução da infância, na pluralidade das suas configurações, 
inscrevem-se em contextos cujas variáveis delimitam perfis diferenciados. A infância é um discurso histórico cuja significação está consignada ao seu contexto e às variáveis de contexto que o definem. Semelhantes contextos são de natureza econômica, social, política cultural, demográfica, pedagógica, etc. É indispensável discernir quais dessas variáveis são de fato atuantes em cada conjuntura e são, conseqüentemente, pertinentes na delimitação do território em causa. Essas variáveis de contexto não são referenciáveis na sua totalidade em cada caso. A sua presença verifica-se diversamente num quadro conjuntural variável.

Até o século XII não existia uma concepção de infância, os estudos apontam que este período da vida ficou obscuro. As representações gráficas relacionadas à iconografia que ilustrava as crianças, com suas particularidades, não eram conhecidas.

Até por volta do século XII, a arte medieval desconhecia a infância ou não tentava representá-la; é difícil acreditar que essa ausência se devesse à falta de habilidade ou de competência. Parece mais provável que a infância não tivesse lugar naquele mundo (ARIÈS, 1973, p. 23 apud CHALMEL, 2004, p. 58).

Áries (198I) destaca que "na sociedade medieval a criança a partir do momento em que passava a agir sem solicitude de sua mãe, ingressava na sociedade dos adultos e não se distinguia mais destes".

Figura I. Concepção de criança século XII

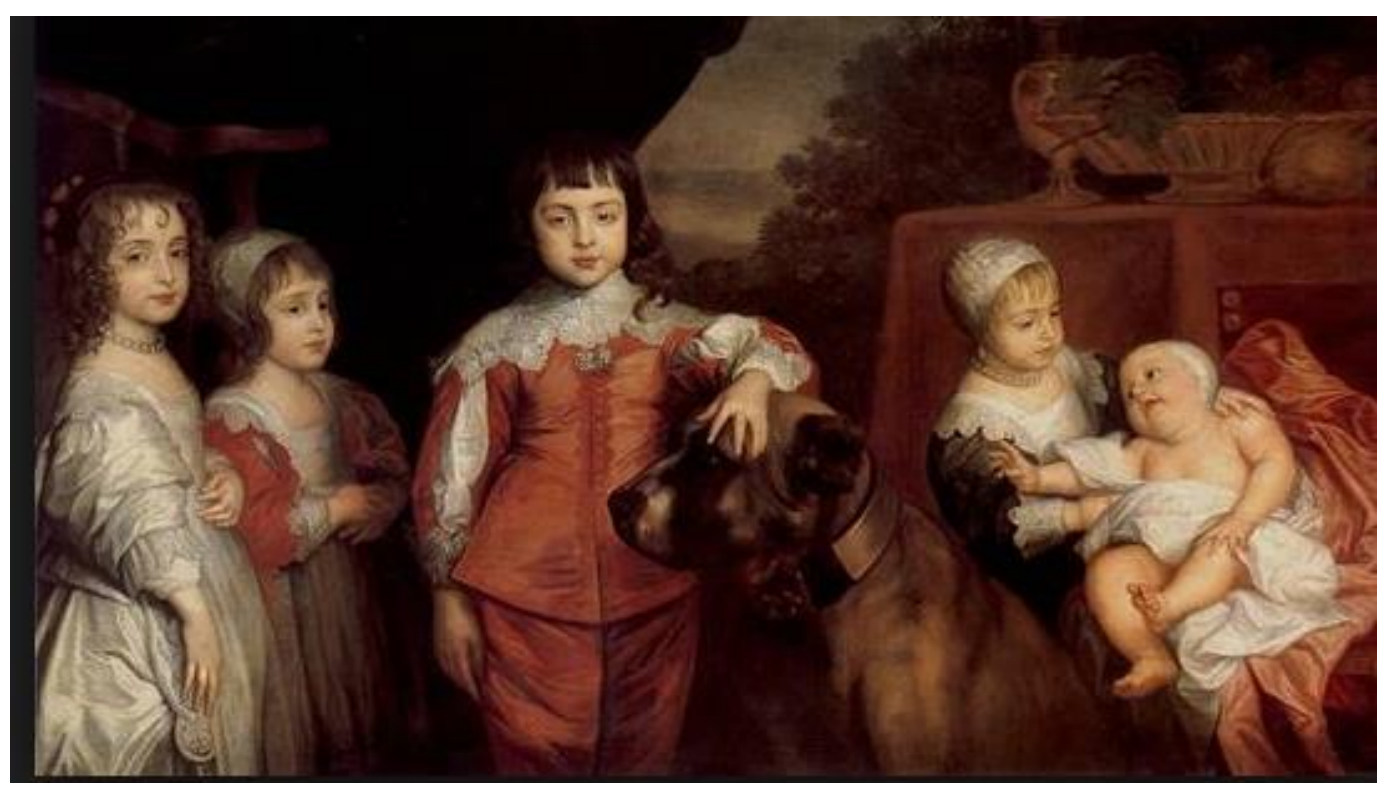

Fonte: https://www.google.com.br

Para este autor as crianças eram representadas como adultos em miniatura, sendo vestidas e expostas aos mesmos costumes dos adultos. Elas não tinham um tratamento diferenciado, nem um mundo próprio, não existia neste período, o chamado sentimento de 
infância.

De acordo com Áries (198I) a relação criança/infância foi se transformando a partir da difusão de novos pensamentos e condutas da Igreja Católica, sendo que estas novas condutas fizeram com que surgissem novos modelos familiares que ressaltavam a importância do laço de sangue. Sendo que no século XVIII a Igreja Católica passou a acusar quem matasse crianças de praticar bruxaria. Desta forma no século X e XI o matrimônio e o ato de procriar passaram a ser considerados sagrados.

A infância passa a ser reconhecida, de acordo com Heywood (2004) a partir do discurso cristão do "culto ao menino Jesus" e do "massacre dos inocentes" praticado por Herodes. De acordo com este autor, passa a se difundir a idéia de que a criança é um mediador do céu e da terra, e que destes vêm falas de sabedoria. Neste cenário, é que aparece sentimento de infância.

Desse modo, o sentimento de infância, conforme conhecemos atualmente, começa a se desenvolver a partir do século XVII. Nesse período, a criança passa a ser percebida a partir de suas especificidades e passa a ocupar lugar central na atenção familiar, sendo fonte de distração e relaxamento para o adulto, passando a ser paparicada, por meio de um sentimento que Ariès (198I) denominou de "paparicação". A partir disso, as famílias passam a dar importância para as crianças e começam a se organizar entorno delas (VEIGA-NETO, et al, 2013, p. 26).

Foi apenas no século XVIII com o surgimento do sentimento de infância, que a concepção de infância se efetivou.

O autor considera mais frutífera a busca de diferentes concepções sobre a infância em diferentes tempos e lugares e identifica várias "descobertas" da infância: nos séculos VI a VII, nos séculos XII a XIV, nos séculos XVI e XVII, no século XVIII e início do XIX, e no final do XIX e início do XX. Para ele, a história da infância se move por "linhas sinuosas", de modo que a criança pode ter sido considerada impura no início do século XX, como o fora na Alta Idade Média. Se há uma mudança de longo prazo em que a progressiva aceitação da necessidade de uma educação escolar prolonga a infância e a adolescência, se há um interesse crescente e uma imagem cada vez mais positiva da infância, os debates assumem uma forma cíclica e não linear. A ambiguidade, nos diferentes momentos, polariza a criança entre a impureza e a inocência, entre as características inatas e as adquiridas, entre a independência e a dependência, entre meninos e meninas (VAZ \& MOMM, 2012, p. 23). 
A partir daí elas passam, do ponto de vista biológico, a ser tratadas com particularidades, a serem percebidas na sua singularidade por possuírem sentimentos próprios.

\begin{abstract}
Uma das principais marcas do pensamento rousseauniano, responsável por boa parte do imediato impacto que a obra causou, advém do fato de ele haver prolongado a acepção de infância - esticou a condição de criança. O Livro II compreende a etapa da formação da puerilidade, que duraria até os 12 anos. Rousseau postula que o menino Emílio não seja aproximado da cultura letrada exatamente como um recurso para ele viver sua infância por mais tempo. A principal tese de Rousseau é a de que, até os I2 anos, a criança terá parâmetros de apreensão de mundo diferentes daqueles presentes nos adultos. Até os I2 anos, ela será conduzida por aquilo que o filósofo acredita ser uma razão sensitiva. Compreender a lógica dessa racionalidade sensível constitui a tarefa primeira do educador. No Livro III do Emílio são desenvolvidos preceitos e práticas de educação (BOTO, 2017, s/p).
\end{abstract}

Após este momento que se introduz políticas destinadas ao desenvolvimento integral do processo infantil, a criança começa ser mais valorizada e respeitada enquanto a fase em que vive para sua melhor formação ao chegar à fase adulta. Deixando-se de lado o passado de séculos atrás e voltando-se o olhar para a atualidade, têm-se a criação da BNCC

(Base Nacional Comum Curricular), que é um documento de caráter normativo que define o conjunto orgânico e progressivo de aprendizagens essenciais que todos os alunos devem desenvolver ao longo das etapas e modalidades da Educação Básica, de modo a que tenham assegurados seus direitos de aprendizagem e desenvolvimento, em conformidade com o que preceitua o Plano Nacional de Educação (PNE).

Para Santos \& Diniz-Pereira (2016, p. 286), a BNCC, defendida como um instrumento importante para a gestão do currículo é uma temática que tem hoje centralidade no debate educacional.

Segundo a página eletrônica do Ministério de Educação (MEC), a BNCC é um documento plural, contemporâneo, e estabelece com clareza o conjunto de aprendizagens essenciais e indispensáveis a que todos os estudantes, crianças, jovens e adultos, têm direito. Com ela, redes de ensino e instituições escolares públicas e particulares passam a ter uma referência nacional obrigatória para a elaboração ou adequação de seus currículos e propostas pedagógicas. Essa referência é o ponto ao qual se quer chegar em cada etapa da Educação Básica.

Este documento normativo aplica-se exclusivamente à educação escolar, tal como a 
define o: $\S$ Io do Artigo Io da Lei de Diretrizes e Bases da Educação Nacional (LDB, Lei no 9.394/1996) e está orientado pelos princípios éticos, políticos e estéticos que visam à formação humana integral e à construção de uma sociedade justa, democrática e inclusiva, como fundamentado nas Diretrizes Curriculares Nacionais da Educação Básica (DCN).

Ao longo da Educação Básica, as aprendizagens essenciais definidas na BNCC devem concorrer para assegurar aos estudantes o desenvolvimento de dez competências gerais, que consubstanciam, no âmbito pedagógico, os direitos de aprendizagem e desenvolvimento. Na BNCC, competência é definida como a mobilização de conhecimentos (conceitos e procedimentos), habilidades (práticas, cognitivas e socioemocionais), atitudes e valores para resolver demandas complexas da vida cotidiana, do pleno exercício da cidadania e do mundo do trabalho.

Segundo as competências gerais descritas pela Base Nacional Comum Curricular tem-se os seguintes objetivos:

I. Valorizar e utilizar os conhecimentos historicamente construídos sobre o mundo físico, social, cultural e digital para entender e explicar a realidade, continuar aprendendo e colaborar para a construção de uma sociedade justa, democrática e inclusiva.

2. Exercitar a curiosidade intelectual e recorrer à abordagem própria das ciências, incluindo a investigação, a reflexão, a análise crítica, a imaginação e a criatividade, para investigar causas, elaborar e testar hipóteses, formular e resolver problemas e criar soluções (inclusive tecnológicas) com base nos conhecimentos das diferentes áreas.

3. Valorizar e fruir as diversas manifestações artísticas e culturais, das locais às mundiais, e também participar de práticas diversificadas da produção artístico-cultural.

4. Utilizar diferentes linguagens verbal (oral ou visual-motora, como Libras, e escrita), corporal, visual, sonora e digital, bem como conhecimentos das linguagens artística, matemática e científica, para se expressar e partilhar informações, experiências, idéias e sentimentos em diferentes contextos e produzir sentidos que levem ao entendimento mútuo.

5. Compreender, utilizar e criar tecnologias digitais de informação e comunicação de forma crítica, significativa, reflexiva e ética nas diversas práticas sociais 
(incluindo as escolares) para se comunicar, acessar e disseminar informações, produzir conhecimentos, resolver problemas e exercer protagonismo e autoria na vida pessoal e coletiva.

6. Valorizar a diversidade de saberes e vivências culturais e apropriar-se de conhecimentos e experiências que lhe possibilitem entender as relações próprias do mundo do trabalho e fazer escolhas alinhadas ao exercício da cidadania e ao seu projeto de vida, com liberdade, autonomia, consciência crítica e responsabilidade.

7. Argumentar com base em fatos, dados e informações confiáveis, para formular, negociar e defender idéias, pontos de vista e decisões comuns que respeitem e promovam os direitos humanos, a consciência socioambiental e o consumo responsável em âmbito local, regional e global, com posicionamento ético em relação ao cuidado de si mesmo, dos outros e do planeta.

8. Conhecer-se, apreciar-se e cuidar de sua saúde física e emocional, compreendendo-se na diversidade humana e reconhecendo suas emoções e as dos outros, com autocrítica e capacidade para lidar com elas.

9. Exercitar a empatia, o diálogo, a resolução de conflitos e a cooperação, fazendo-se respeitar e promovendo o respeito ao outro e aos direitos humanos, com acolhimento e valorização da diversidade de indivíduos e de grupos sociais, seus saberes, identidades, culturas e potencialidades, sem preconceitos de qualquer natureza.

ıo. Agir pessoal e coletivamente com autonomia, responsabilidade, flexibilidade, resiliência e determinação, tomando decisões com base em princípios éticos, democráticos, inclusivos, sustentáveis e solidários.

O próprio documento da BNCC diz que a que a Educação Básica deve estar voltada para a formação e desenvolvimento de toda a pessoa, ou seja, compreender a complexidade e não linearidade desse desenvolvimento, rompendo com conceitos reducionistas que privilegiam a dimensão intelectual (cognitiva) e emocional. Trata-se de assumir uma visão plural, singular e integral de crianças, adolescentes, jovens e adultos como objetos de aprendizagem, e promover uma educação voltada para seu acolhimento, seu reconhecimento e seu pleno desenvolvimento, em suas singularidades. Além disso, a escola, como espaço democrático inclusivo e de aprendizagem, deve ser fortalecida em 
práticas coercitivas de não discriminação, não prejudiciais e que respeitem as diferenças e a diversidade.

\section{CONCLUSÃO}

A realização do presente artigo permitiu conhecer as concepções atuais de educação, que consideram as crianças como ser histórico-social que são determinadas por diversos fatores, seja eles social, econômico, cultural e político. Com base nesse desígnio desenvolve uma visão romântica da infância, com aspetos de encantamento e ludicidade, bem como outras características existentes em determinados contextos sociais.

A criança no decorrer dos tempos passou a ser considerada e dotada de competência, com necessidades, modo peculiar de pensar e agir, modos próprios da infância.

Os aspectos de infância modificam de acordo com o lugar que a criança ocupa na família, na classe social, a questão de gênero, etnia, grupo etário, na sociedade em geral.

Dessa forma, podemos observar os contrastes em relação ao sentimento de infância presente em determinados momentos da história. Algumas atitudes que atualmente são consideradas anormais, como o tratamento indiferente à criança pequena, alguns séculos atrás era concebido como normal.

A sociedade nem sempre enxergava a criança como um sujeito com singularidades que requeria cuidados específicos. Por muito tempo era tratada como um adulto em miniatura. Para transformar essa concepção assistencialista, existiu uma mudança na educação infantil. Era imprescindível olhar e aceitar as suas especificidades e repensarem quais era as responsabilidades da sociedade e o real papel do Estado perante as crianças pequenas. A educação para as crianças pequenas precisa objetivar a integração entre os vários aspectos que as norteiam, como o aspecto físico, emocional, cognitivo, entre outros.

A leitura da Base Nacional Comum Curricular (BNCC) é importante para aqueles que pretendem serem futuros profissionais da educação, uma vez que esse documento sinaliza as deliberações pedagógicas necessárias ao desenvolvimento de competências, que garantam as aprendizagens fundamentais determinadas neste documento. 


\section{REFERÊNCIAS}

BARROS, Flávia Cristina Oliveira Murbach de. Cadê o brincar?: da educação infantil para o ensino fundamental. São Paulo: Cultura Acadêmica, 2009.

BOTO, Carlota. Instrução pública e projeto civilizador: o século XVIII como intérprete da ciência, da infância e da escola. São Paulo: Editora Unesp Digital, 2017.

BRASIL. Base Nacional Comum Curricular (BNCC). Educação é a Base. Brasília, MEC/CONSED/UNDIME, 2017. Disponível em: http://educere.bruc.com.br. Acesso em: 22/o9/2021.

BRASIL. Ministério da Educação. Base Nacional Comum Curricular: Educação é a base. Disponível em: http://basenacionalcomum.mec.gov.br. Acesso em: 2I/o9/202I.

CHALMEL, Loic. Imagens de crianças e crianças nas imagens: representações da infância na iconografia pedagógica nos séculos XVII e XVIII. Educ. Soc., Campinas, vol. 25, n. 86, p. 57-74, abril 2004. Disponível em: http://www.scielo.br. Acesso em; 24/o9/202I.

FARIA FILHO, Luciano Mendes de. A infância e sua educação: materiais, práticas e representações (Portugal e Brasil). Belo Horizonte: Autêntica, 2004.

MIMESSE, Eliane. Bambini brasiliani: a Infância das crianças italianas e ítalo-brasileiras. Jundiaí, Paco Editorial: 2013.

NIEHUES, Mariane Rocha; COSTA, Marli de Oliveira. Concepções de infância ao longo da história. Rev. Técnico Científica (IFSC), v. 3, n. I (2012). Disponível em: https://periodicos.ifsc.edu.br/. Acesso em: 24/o9/2021.

PORTILHO, Evelise Maria Labatut. (org.) Formação continuada na educação infantil: outros olhares sobre as crianças e as infâncias. 2. ed. Curitiba, Appris, 2017. 
SANTOS, Lucíola Licínio de Castro Paixão; DINIZ-PEREIRA, Júlio Emílio. Tentativas de padronização do currículo e da formação de professores no Brasil. Santosı Cad. Cedes, Campinas, v. 36, n. Ioo, p. 281-30o, set.-dez., 2016. Disponível em: http://www.scielo.br. Acesso em: 2I/o9/2021.

VAZ, Alexandre; MOMM, Caroline Machado. (orgs.) Educação infantil e sociedade: questões contemporâneas. Nova Petrópolis: Nova Harmonia, 2012.

VEIGA-NETO, Alfredo José da. et al. Infância(s), educação e governamento. Rio Grande: Universidade Federal do Rio Grande, 2013. Disponível em: http://www.sead.furg.br. Acesso em: 24/o9/2021. 